\title{
Mystère et Noël, textes réunis par Xavier Leroux
}

\section{Elena La Rocca}

\section{(2) OpenEdition}

\section{Journals}

\section{Edizione digitale}

URL: http://journals.openedition.org/studifrancesi/1100

DOI: 10.4000/studifrancesi. 1100

ISSN: 2421-5856

\section{Editore}

Rosenberg \& Sellier

\section{Edizione cartacea}

Data di pubblicazione: 1 novembre 2014

Paginazione: 575

ISSN: 0039-2944

\section{Notizia bibliografica digitale}

Elena La Rocca, " Mystère et Noël, textes réunis par Xavier Leroux », Studi Francesi [Online], 174 (LVIII I

III) | 2014, online dal 01 novembre 2014, consultato il 18 septembre 2020. URL : http://

journals.openedition.org/studifrancesi/1100; DOI : https://doi.org/10.4000/studifrancesi.1100

\section{Questo documento è stato generato automaticamente il 18 settembre 2020.}

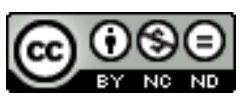

Studi Francesi è distribuita con Licenza Creative Commons Attribuzione - Non commerciale - Non opere derivate 4.0 Internazionale. 


\title{
Mystère et Noël, textes réunis par Xavier Leroux
}

\author{
Elena La Rocca
}

\section{NOTIZIA}

Mystère et Noël, textes réunis par XAVIER LEROUX, «Revue des langues romanes», CXVII, n. 1, 2013.

1 Questo numero della «Revue des langues romanes» si propone di studiare alcune riscritture teatrali di episodi biblici, al fine di individuare gli scambi e la circolazione delle opere tra Francia settentrionale e Francia meridionale nel xv secolo.

2 Il contributo di Nadine HENRARD, Les versions dramatiques de la legénde de saint André (pp. 5-26) passa in rassegna le trasposizioni drammatiche della leggenda di Sant'Andrea e individua i legami che esse intrattengono tra loro e gli scambi che si sono verificati su questa materia tra la Francia del Nord, il Delfinato e le valli del Piemonte. I testi presi in esame sono la prima forma teatrale conservata della leggenda, ossia Le Mystère des Actes des Apôtres (un mystère di ambiente briançonnais), La passion de saint André occitane, che costituisce una testimonianza di quanto il repertorio francese abbia influenzato il teatro occitano, la Vie et mistere de saint Andry, trasmesso tramite un testo a stampa e collocato in un contesto più urbano, infine l'Histoire de saint André jouée aux Ramats, che è la riscrittura più interessante per quanto concerne i rapporti e gli scambi tra le diverse regioni francesi. Infatti quest'ultimo testo è stato messo in scena nel comune di Chaumont in val di Susa e dimostra la vivacità degli scambi culturali tra le regioni settentrionali della Francia e le valli piemontesi, vivacità che ha permesso la sopravvivenza dei misteri almeno fino al XVIII secolo.

Il contributo di Xavier LEROUX (Des vers sans rime ni raison? Remarques sur les vers dit 'orphelins' dans les mystères du Moyen Âge, pp. 27-48) prende in considerazione alcune irregolarità metriche frequenti nei misteri in lingua d'oïl, utilizzando come testo di riferimento Le mystère de la Conception. In particolare lo studioso vuole dimostrare che i 
versi definiti orphelins non sono semplicemente versi che non rimano, ma sono caratterizzati anche da dissimmetrie nella loro struttura, le quali coinvolgono aspetti sintattici, drammaturgici e talvolta morfologici.

4 Francesc MASSIP nel suo articolo La sibille tiburtine dans les mystères de la Nativité et de l'Épiphanie (pp. 49-78) inquadra la figura della sibilla tiburtina, personaggio dapprima pagano e poi cristianizzato, all'interno dei misteri della Natività e dell'Epifania. La fonte di queste riscritture è la leggenda romana dell'Ara Coeli, secondo la quale, nel consulto richiestole dall'imperatore Augusto prima di accettare il potere che il senato voleva attribuirgli, la sibilla cerca di dissuaderlo prefigurandogli la venuta di Cristo, il vero re. Questa storia dà vita ad un nuovo genere di rappresentazione drammatica per la notte di Natale. Qui la sibilla diventa uno strumento di catechismo, in quanto tramite l'insegnamento all'imperatore pagano conferma la verità cristiana allo spettatore.

5 Lo studio di Paola CIFARELLI, Le noël et ses rapports avec le Mystère: quelques réflexions (pp. 79-101) individua alcune caratteristiche specifiche del genere del noël, che ha come tema la nascita di Cristo, sottolineando le differenze rispetto ai mystères che trattano lo stesso soggetto. L'analisi è condotta su un corpus di testi situati cronologicamente alla fine del $\mathrm{XV}$ secolo, in quanto proprio in questa fase storica sono contemporaneamente presenti i mystères sulla Natività e le Passions che comprendono episodi sulla nascita di Gesù. La comparazione prende in esame le Passions di Eustache Marcadé e di Arnoul Gréban, le Passions di Troyes e di Semur, tre mystères sulla Natività (ms. 1131 Bibliothèque Sainte-Geneviève, un mystère messo in scena a Rouen e il frammento conosciuto come il Jeu de l'Etoile, pubblicato da Claude Thiry nel 1971), oltre al Mystère de la Conception (ms. 616 Musée Condé di Chantilly e versione a stampa del 1507). Attraverso la messa in discussione di alcuni punti fermi della critica su questi generi teatrali, emergono alcune considerazioni interessanti: il noël, inteso come genere autonomo, coesiste già a partire dal XV secolo con i mystères, la sua forma presenta in realtà pochi elementi propri del teatro (almeno prima del 1550), in quanto predilige la narrazione al dialogo; infine viene analizzata la presenza di fonti profane per la composizione delle musiche, riproposte con un fine edificante.

Marina fEy (La Nativité de Bathélemy Aneau, pp. 103-117) offre un'analisi del Chant Natal, la cui prima edizione a stampa data del 1535, composto da Barthélemy Aneau, una delle figure di spicco del panorama culturale lionese nella prima metà del Xvi secolo. L'opera è particolarmente interessante in quanto è uno dei pochi esempi di testo ibrido, ossia di dramma che unisce alcuni elementi del noël ad altri del mystère. La sua data di composizione lascia intendere che si tratta di un testo inserito in un contesto storicoculturale diverso rispetto ai noëls e ai mystères medievali: esso presenta infatti elementi pienamente rinascimentali. Lo studio vuole dimostrare che i due generi, pur trattando $\mathrm{i}$ medesimi temi, mantengono caratteristiche specifiche e che solo la bergerie, nella quale si può far rientrare il testo di Aneau, costituisce un punto di incontro. 